\title{
Ciclos Políticos nas Funções Orçamentárias dos Municípios Brasileiros: Uma Análise para o Período 1990 - 2005 Via Dados em Painel ${ }^{\star}$
}

\author{
- Sergio Naruhiko Sakural *
}

\begin{abstract}
RESUMO
A investigação de evidências de ciclos eleitorais e partidários nas funções orçamentárias dos municípios brasileiros, entre os anos de 1990 e 2005, é o propósito fundamental deste artigo. Os resultados indicam que o primeiro fenômeno é observado de forma mais expressiva nas funções saúde e saneamento, habitação e urbanismo, assistência e previdência e transportes, ao passo que em relação aos ciclos partidários, os resultados permitem observar a influência, ainda que relativa, das distinções partidárias sobre a forma pela qual os recursos são alocados entre as funções avaliadas. Adicionalmente, os resultados evidenciam uma recomposição das despesas municipais ao longo do tempo, influenciada também pela instituição da Lei de Responsabilidade Fiscal.
\end{abstract}

\section{Palavras-Chave}

ciclos políticos, finanças públicas municipais, dados em painel

\section{ABSTRACT}

The main purpose of the present study is an investigation concerning the possibility of electoral and partisan cycles in the budgetary functions of Brazilian cities over the $1990-2005$ period. For the first phenomenon, the econometric results provide evidence that health and sanitation, housing and urbanism, social assistance \& retirement system and transports are the most susceptible functions to changes in election years. With reference to the partisan cycles, the influence of partisanship heterogeneity on the municipal expenditures is furthermore suggested by the outcomes. Finally, we have found indication of an expenditure composition effect over the time, also influenced by the Brazilian Law of Fiscal Responsibility.

\section{KEYWORDS}

political cycles, municipal public budget, panel data

\section{JEL CLASSIFICATION}

E32, $\mathrm{H} 72, \mathrm{C} 23$

\footnotetext{
+ $\quad$ autor agradece os comentários de dois pareceristas anônimos desta publicação eximindo-os, certamente, de qualquer erro remanescente.

* Departamento de Economia. Faculdade de Economia, Administração e Contabilidade de Ribeirão Preto - FEA-RP/ USP. Endereço para contato: Avenida dos Bandeirantes, 3900. Ribeirão Preto - SP. E-mail: sakurai@usp.br.

(Recebido em julho de 2007. Aceito para publicação em abril de 2008).
} 


\section{INTRODUÇÃO E REVISÃO DA LITERATURA}

A percepção de que o comportamento da economia tanto influencia como é influenciado pelo comportamento dos agentes políticos é bastante difundida e, de fato, evidências que corroboram tal hipótese não raramente são observadas. Tufte (1978) pode ser considerado um dos primeiros estudos em que tal relação é analisada de maneira mais formal e criteriosa, embora esta seja apenas uma das várias referências que procuram argumentar sobre a relevância desta interação. De todo modo, muitos dos modelos macroeconômicos assumem que policymakers benevolentes visam prioritariamente obter o melhor resultado para a sociedade, mas caso outros fatores inerentes a decisões coletivas sejam considerados, tais conclusões podem se tornar distintas.

Definindo genericamente como ciclos políticos a possibilidade de fatores políticos afetarem o comportamento das variáveis econômicas, a literatura pode ser dividida em basicamente duas partes. A escola de análise relacionada à existência de incentivos oportunistas pode ser caracterizada por considerar o pressuposto de que policymakers, independentemente de ideologia partidária, visam implícita e fundamentalmente manter-se no poder. Assim, os denominados ciclos eleitorais seriam resultantes de ações promovidas pelos governantes para obter uma probabilidade maior de permanência no poder. Esta corrente analítica pode ser dividida em duas abordagens, uma considerando expectativas adaptativas (NORDHAUS, 1975) e outra considerando expectativas racionais (ROGOFF; SIBERT, 1988 e ROGOFF; 1990), mas ambas procurando justificar a existência de ciclos econômicos em função do calendário eleitoral. De acordo com a primeira destas referências, em um ambiente em que os demais agentes econômicos formam suas expectativas de forma adaptativa, políticos conseguem estabelecer um determinado padrão cíclico no comportamento da economia em função do calendário eleitoral, ao passo que Rogoff e Sibert (1988) e Rogoff (1990) consideram que a existência dos ciclos econômicos como função do calendário eleitoral é determinada não pela "não racionalidade" dos agentes econômicos, mas fundamentalmente pela questão da assimetria de informações entre policymakers e eleitores, ou seja, os eleitores são influenciados pelos políticos uma vez que, ao menos momentaneamente, não possuem todas as informações disponíveis para avaliar a competência de um candidato à permanência no poder.

Paralelamente ao desenvolvimento da abordagem teórica que analisa elementos de ordem oportunista na determinação de ciclos econômicos, a segunda vertente teórica procura enfatizar as diferenças ideológicas ou, mais explicitamente, partidárias, e a possibilidade de este fator afetar o comportamento da economia. Neste caso, as referências básicas são os trabalhos de Hibbs (1977), também considerando o pressuposto de expectativas adaptativas, e Alesina (1987), no caso dos modelos 
pressupondo expectativas racionais. De acordo com esta abordagem, os partidos políticos apresentariam preferências diferentes em relação à conduta de suas respectivas políticas econômicas e, assim, existiria um comportamento distinto da economia em função de uma consistência ideológica por parte dos partidos políticos, uma vez estando no poder. De acordo com Hibbs (1977), a simples diferenciação existente entre os partidos políticos seria condição suficiente para gerar os denominados ciclos partidários, enquanto para Alesina (1987) os ciclos partidários seriam mais contundentes em situações em que os resultados eleitorais fossem mais incertos, ou seja, em que a incerteza sobre o partido a assumir o poder é maior. Conforme tal incerteza diminui ou conforme o comportamento partidário é internalizado pelos indivíduos, menores tendem a ser tais flutuações.

Em termos empíricos, as evidências sugerem resultados distintos sobre a possibilidade dos ciclos políticos. Em Berger e Woitek (1997), por exemplo, são encontradas evidências de expansões do produto agregado nos períodos anteriores às eleições alemãs. Já em Alesina, Roubini e Cohen (1997), os resultados indicam a ausência dos ciclos eleitorais nos países da OCDE sugerindo, por outro lado, a influência das diferenças partidárias sobre o comportamento destas economias. Por sua vez, a literatura mais recente tem procurado analisar o comportamento fiscal através da análise de bases de dados que contemplam países de diferentes graus de desenvolvimento econômico, como ocorre em Shi e Svensson (2002), por exemplo, que encontram evidências de deterioração fiscal em períodos pré-eleitorais, ao passo que em Persson e Tabellini (2003) são observadas evidências de redução da carga tributária antes das eleições. Contudo, Brender e Drazen (2003) demonstram que tal resultado é observado devido basicamente ao comportamento dos países em que o regime democrático ainda é recente, uma vez que nos países com regimes democráticos mais sólidos o fenômeno do ciclo eleitoral tende a ser inexistente.

Neste contexto, a análise do comportamento fiscal dos municípios brasileiros tornase especialmente relevante em função da relativa ausência, na literatura brasileira, de estudos que promovam a análise da interação entre elementos de ordem econômica e elementos de ordem política em tais localidades. Explicitamente, um primeiro elemento que demonstra a relevância da análise dos municípios está no fato de que, dada a maior proximidade dos indivíduos em relação a estas esferas do poder político (comparativamente aos governos estadual e federal) é razoável considerar a hipótese de que a demanda da sociedade por recursos públicos recaia principalmente sobre a administração municipal. ${ }^{l}$ Adicionalmente, outra justificativa para o estudo dos municípios reside na percepção de que, particularmente no caso dos policymakers, é

1 Este argumento é notadamente relevante dado que a Constituição de 1988 efetivamente alterou a posição dos municípios brasileiros dentro do arranjo federativo, ao fazer com que a provisão de um conjunto relevante de serviços públicos passasse a ser feita pela administração municipal. 
razoável considerar que seu sucesso e ascensão política muitas vezes estão condicionados ao sucesso que estes obtêm na administração de instâncias menos agregadas do poder político. Por fim, especificamente a respeito dos ciclos eleitorais, um fator relevante a ser considerado no caso brasileiro é o caráter exógeno do calendário eleitoral. No caso brasileiro, todas as eleições (para os governos federal, estadual e municipal, tanto para o Executivo como para o Legislativo) são realizadas periodicamente em datas (anos) predefinidas sendo, portanto, previamente conhecida pelos agentes. No caso do contexto brasileiro, esta característica pode permitir à classe política ajustar o timing das políticas implementadas, de modo que os resultados obtidos possam ser posteriormente vinculados a uma popularidade maior das mesmas e consequentemente, a uma probabilidade maior de permanência no poder. Isto é especialmente provável no caso brasileiro uma vez que (i) as eleições são normalmente realizadas somente em outubro de um dado ano eleitoral e (ii) o ano calendário da execução fiscal coincide com o ano calendário civil, ou seja, existe a possibilidade de que a despesa municipal executada entre janeiro e outubro possa efetivamente influenciar as escolhas dos eleitores. Assim, se estas percepções são condizentes, a probabilidade de que o comportamento destes níveis menos agregados do poder político esteja relacionado a fatores de natureza política pode ser não-desprezível.

No que diz respeito aos estudos aplicados em níveis menos concentrados de governo, as referências da literatura brasileira são relativamente mais recentes. Um estudo que pode ser considerado relevante neste contexto é o trabalho realizado por Cossio (2001), no qual é constituído um painel para variáveis fiscais para o período que compreende os anos de 1985 a 1997 e são encontradas evidências que sugerem a existência de impulsos positivos de despesa em anos eleitorais, bem como indícios de que um maior grau de participação da sociedade no processo político (nas eleições) levaria a uma maior disciplina fiscal dos governadores brasileiros. Adicionalmente, são obtidas evidências de que uma dificuldade maior em formar maiorias de governo nos Legislativos de cada Estado brasileiro está relacionada de forma positiva com o volume de gastos, ou seja, assembléias legislativas mais fragmentadas (em termos partidários) tendem a gerar maior dificuldade em realizar programas de ajuste fiscal. Neste estudo, não é encontrada nenhuma evidência de distinção físcal devido aos partidos políticos dos governadores, ou seja, não há nenhuma caracterização mais contundente dos ciclos partidários. Finalmente, a coincidência do partido do governador e do partido do presidente da República sugere um maior ajuste fiscal observado nos Estados brasileiros.

Um segundo trabalho relevante neste contexto é a investigação dos determinantes do déficit público conforme realizada por Botelho (2002), no qual é analisado um painel composto pelos Estados brasileiros entre 1986 e 2000. Segundo os resultados obtidos por tal autor, o ano eleitoral é um ano de forte ampliação dos déficits e o ano 
antes das eleições é um ano em que um certo ajuste é feito como forma de canalizar recursos para o ano seguinte. Já em relação à possibilidade dos ciclos partidários, não foi encontrada significância estatística da variável referente à ideologia.

Uma referência adicional para o caso dos Estados brasileiros é o trabalho de Nakaguma (2006), no qual são investigados componentes específicos do orçamento de tais unidades durante o período 1986-2004. Os resultados obtidos indicam um aumento da despesa orçamentária (via aumentos da despesa corrente e de custeio) nos anos eleitorais, sendo observada uma queda da despesa de capital no ano posterior ao ano eleitoral, sugerindo, assim, a existência de um ajuste fiscal pós-eleição através da redução dos investimentos públicos. Por sua vez, e de forma oposta à obtida por Meneguin e Bugarin (2001), é observado um aumento da despesa orçamentária (também via aumentos da despesa corrente e da despesa de custeio) no caso de o governador concorrer à reeleição, o que indica que a possibilidade de permanência no poder gera estímulos para manipulações fiscais. Finalmente, a Lei de Responsabilidade Fiscal provocou redução significativa da despesa de custeio dos Estados brasileiros. Os resultados deste estudo permitem, ainda, observar que partidos de esquerda apresentam efetivamente maior grau de intervenção na economia, através tanto de maior arrecadação de recursos como também de maior execução fiscal. Um outro resultado relevante diz respeito ao fato de que a ocorrência dos ciclos eleitorais sofre redução ao longo do tempo, sugerindo, assim, que o aprendizado e a experiência obtidos com a continuidade do processo eleitoral podem restringir a possibilidade de manipulações por parte dos políticos, conforme Brender e Drazen (2003).

Por fim, um trabalho que aborda de forma específica o caso dos municípios brasileiros é Sakurai (2007), no qual é analisado o comportamento fiscal das unidades locais paulistas entre 1989 e 2001 . Os resultados do estudo sugerem que para a despesa orçamentária e para a despesa corrente são observados impulsos de gastos nos anos eleitorais de 1992 e 1996, embora tal comportamento não seja observado no caso da despesa de pessoal, transferências correntes e despesa de investimento. No que diz respeito ao teste para os partidos políticos, os resultados obtidos demonstram algumas distinções particulares, como por exemplo, o fato de o PT ser o partido que menos gasta em transferências correntes; as maiores despesas agregadas do PFL têm como origem seus maiores gastos em investimentos públicos; os maiores gastos agregados observados para o PTB e para o PPB / PDS têm como origem seus maiores gastos em despesas de pessoal e, finalmente, o PSDB também se destaca por despender maiores recursos em despesas de pessoal. Por fim, os resultados também sugerem que o alinhamento partidário entre os prefeitos e o governador estadual não influencia o comportamento das variáveis supracitadas, dentro do período analisado. 
Dadas tais considerações, finaliza-se aqui esta introdução e breve revisão da literatura. O presente estudo contém, adicionalmente, outras três seções: o referencial metodológico é apresentado na seção 2 e os resultados das estimações são apresentados na seção 3. Finalmente, a seção 4 apresenta as considerações finais deste artigo.

\section{ASPECTOS METODOLÓGICOS}

Este artigo contempla as despesas de $5506^{2}$ municípios brasileiros, decompostas por funções administrativas, entre os anos de 1990 e 2005. Tal abordagem tem como referência o trabalho recente de Drazen e Eslava (2005), segundo o qual alterações fiscais com interesses oportunistas seriam realizadas de forma a alterar a composição das despesas públicas e, assim, direcionar maiores recursos aos tipos de despesas mais desejadas pelos eleitores. Aplicando os resultados do modelo teórico para o caso dos municípios colombianos entre os anos de 1987 e 2000, os resultados obtidos por tais autores sugerem que anteriormente às eleições daquelas localidades os gastos de natureza corrente (principalmente transferências a idosos e pagamentos de funcionários temporários) sofrem redução, ao passo que os investimentos (construção de rodovias e unidades de geração de energia elétrica, entre outros) tendem a aumentar. Assim, em anos eleitorais, tais evidências corroboram a hipótese de realocação de recursos dentro do orçamento público com prováveis razões oportunistas.

As hipóteses principais a serem testadas nesta avaliação podem ser classificadas em basicamente duas, conforme apresentadas na revisão da literatura. A primeira possibilidade seria a de que algumas funções orçamentárias poderiam ser conduzidas em função de eventuais interesses eleitorais por parte das administrações das referidas unidades, em consonância com o que argumenta a teoria dos ciclos políticos oportunistas. Por outro lado, a segunda possibilidade está associada ao fato de que algumas categorias de despesa pública poderiam ser mais ou menos priorizadas em função da estrutura de preferências destas mesmas administrações ou, em outros termos, das opções partidárias dos prefeitos brasileiros. Assim, esta segunda possibilidade permite investigar se as despesas dos municípios brasileiros estariam sujeitas ao fenômeno dos ciclos políticos partidários. Dada a estrutura dos dados disponíveis, que inclui informações sobre os municípios brasileiros ao longo do período citado, utilizam-se as técnicas tradicionais ${ }^{3}$ de regressão econométrica para dados em painel, de modo

2 Em função do fato de que alguns municípios foram criados ao longo deste período, a amostra vem a ser um painel não balanceado, ou seja, uma amostra na qual inexistem alguns municípios em alguns anos (os primeiros da amostra, basicamente).

3 Quais sejam, efeitos fixos e efeitos aleatórios. Foi também utilizado o tratamento clássico de dados agrupados (pooled OLS). 
a permitir que as regressões sejam controladas pelas características não-observáveis e intrínsecas a cada unidade seccional (no caso, os municípios brasileiros) avaliada.

São estimadas oito regressões em que as variáveis dependentes são as despesas municipais categorizadas pelo critério de funções orçamentárias. Efetivamente, nem todas as funções são apresentadas neste estudo, embora os testes econométricos tenham sido aplicados às mesmas - são aqui expostos somente os casos em que há alguma evidência de ciclos eleitorais ou partidários ${ }^{4}$. Assim, as funções avaliadas são:

1. Agricultura

2. Saúde e Saneamento

3. Transporte

4. Assistência e Previdência

5. Comunicações

6. Habitação e Urbanismo

7. Legislativo

8. Educação e Cultura

Considerando os objetivos primários deste estudo, existem dois procedimentos de interesse. O primeiro diz respeito à inclusão de uma dummy que assume o valor 1 (um) nos anos de eleições municipais (1992, 1996, 2000 e 2004) e 0 caso contrário, de modo a testar se, em média, as despesas executadas em tais anos especificamente são diferentes daquelas executadas nos anos não-eleitorais. $\mathrm{O}$ segundo, por sua vez, é a inclusão de dummies para cada grupo ideológico de partidos políticos, quais sejam, esquerda, centro e direita. A classificação aqui utilizada segue aquela constituída por Rodrigues (2002), conforme a Tabela 1 em sequência, sendo importante ressaltar que os demais partidos existentes na amostra e não classificados por tal referência foram incluídos numa única dummy, denominada "outros partidos". Através deste procedimento, as estimações procuram identificar se as diferenças partidárias causam alguma influência no comportamento das funções orçamentárias a serem analisadas, em alusão ao fenômeno dos ciclos partidários, de forma semelhante àquela utilizada em outros estudos, como por exemplo, Nakaguma (2006), Bittencourt (2002) e Cossio (2001).

4 No caso das funções energia, indústria, comércio e serviços, trabalho e defesa e segurança pública, os valores do $\mathrm{R}^{2}$ das regressôes foi irrisório e as evidências de ciclos políticos foram insignificantes. Tais resultados estão disponíveis aos interessados mediante solicitação ao autor. 


\section{TABELA I-CLASSIFICAÇÃO DOS PARTIDOS POLÍTICOS}

\begin{tabular}{ccc}
\hline Esquerda & Centro & Direita \\
\hline PT & PMDB & PFL \\
PDT & PSDB & PPB \\
PSB & PTB & PL \\
PC do B & & PSD \\
PPS & & PSC \\
PMN & & Prona \\
PV & & PSL \\
& & PST \\
\hline
\end{tabular}

Fonte: Rodrigues (2002)

As variáveis de controle incluídas nas estimações são (i) receita tributária, (ii) receita de transferências correntes (oriundas da União e dos respectivos governos estaduais), (iii) proporção de jovens e (iv) proporção de idosos residindo no município, (v) grau de urbanização do município, (vi) população total (em logaritmo natural) do município, (vii) PIB nacional. ${ }^{5}$ Adicionalmente, duas dummies políticas: (viii) uma dummy que assume o valor $\mathrm{l}$ (um) caso o prefeito seja membro de algum partido que tenha feito parte da coalizão (coligação) que elegeu o governador estadual (0 caso contrário) e (ix) uma dummy que assume o valor 1 caso o prefeito seja membro de algum partido que tenha feito parte da coalizão que elegeu o presidente da República ( 0 caso contrário). Desta forma, subentende-se que independentemente de razões eleitorais ou partidárias, um município tende a ter um maior ou menor volume de despesa pública executada a depender de como se comportam tais variáveis. Adicionalmente, apesar de serem variáveis de controle, resultados particulares podem ser providos por estas variáveis: no caso das receitas, por exemplo (tributária e de transferências), é possível analisar como cada um destes recursos são alocados entre as funções aqui consideradas, ou seja, é possível avaliar um eventual efeito "composição" das receitas municipais entre as funções orçamentárias. Por outro lado, as variáveis de natureza demográfica ${ }^{6}$ permitem avaliar a forma com que estas tendem a afetar a alocação e a execução dos recursos à disposição das prefeituras brasileiras.

Especificamente a respeito do alinhamento partidário com o governo estadual e federal, tal análise pode evidenciar resultados adicionais sobre como fatores de natureza política podem afetar a gestão do orçamento público principalmente quando se considera a elevada dependência política e econômica dos municípios brasileiros (os menores, principalmente) em relação aos níveis mais elevados do poder político, justificando assim a inclusão destes termos. Finalmente, com vistas a controlar por eventuais tendências de crescimento ou decrescimento de cada uma das funções

5 A inclusão desta variável segue os trabalhos de Nakaguma (2006) e Botelho (2002), entre outros.

6 Consideradas, entre outros, por Shi e Svensson (2002) e Persson e Tabellini (2003) 
orçamentárias ao longo dos 16 anos existentes na amostra, foram incluídos também um termo de tendência linear e um termo de tendência quadrática nas estimações.

Uma última análise a ser considerada neste estudo diz respeito à instituição da Lei de Responsabilidade Fiscal (LRF) e a influência deste elemento sobre o comportamento das finanças públicas dos municípios brasileiros. Com o objetivo de captar o eventual efeito desta instituição sobre as funções orçamentárias aqui avaliadas, as estimações incluem também uma dummy que assume o valor 1 nos anos entre 2000 (este inclusive) $^{7}$ e 2005, anos em que LRF tem vigorado, e assume o valor 0 nos demais anos.

As informações de natureza fiscal, ${ }^{8}$ todas transformadas em valores per capita, foram obtidas através de duas fontes básicas, quais sejam, a base de informações regionais mantida pelo Instituto de Pesquisa Econômica Aplicada (Ipeadata) e os dados de execuções físcais dos municípios brasileiros disponibilizados pela Secretaria do Tesouro Nacional (STN), ambas em seus respectivos sites da internet. ${ }^{9}$ As variáveis de natureza demográfica foram constituídas com base nos dados disponibilizados pelo Instituto Brasileiro de Geografia e Estatística (IBGE). ${ }^{10}$ Finalmente, as informações de natureza política foram obtidas através das informações disponibilizadas pelo Tribunal Superior Eleitoral (TSE), pelo Tribunal Regional Eleitoral (TRE) dos Estados brasileiros e pelo cientista político Jairo Nicolau. ${ }^{11}$ É importante ressaltar que este estudo considera os resultados das eleições municipais de 1988 e 1992 , informações significativamente particulares cuja avaliação pode prover resultados significativos para a literatura referente, justamente pela ausência de trabalhos (ao menos nesta linha de pesquisa) que contemplem tais dados.

\section{3 APRESENTAÇÃO E ANÁLISE DOS RESULTADOS ${ }^{12}$}

A Tabela 2 apresenta os resultados das oito estimações, em que os valores entre parênteses são os desvios padrão associados a cada coeficiente. São apresentadas

7 De acordo com Nunes e Nunes (2003), a LRF entrou em vigor em maio de 2000 e, apesar de no primeiro ano o ajuste fiscal ter sido parcial porque as administraçôes já trabalhavam com orçamentos aprovados no ano anterior, muitos ajustes que não dependiam dos orçamentos foram efetivamente realizados. Logo, são observadas ações de conservadorismo fiscal já no próprio ano de aprovação da lei.

8 As informaçỗes fiscais foram corrigidas de acordo com o IGP - DI e estão em R\$ de 2006.

9 Ver, respectivamente, http://www.ipeadata.gov.br/ipeaweb.dll/MenuCtrl?SessionID=0\&Mod=REGI ONAL\&Lang= e http://www.stn.fazenda.gov.br/estados_municipios/index.asp

10 Censos de 1991 e 2000 e Contagem Populacional de $199 \overline{6}$.

11 As informaçôes obtidas através desta fonte são aquelas referentes às coligações dos governos estaduais e do governo federal. Para maiores detalhes, ver http://jaironicolau.iuperj.br/home.html

12 Para os resultados obtidos, considere:

$*_{* *}^{* *}$ : coeficiente estatisticamente significante a $1 \%$

** : coeficiente estatisticamente significante a $5 \%$

${ }^{*}$ : coeficiente estatisticamente significante a $10 \%$ 
também as estatísticas do teste de Hausman, ${ }^{13}$ que em todos os casos aponta para a consistência dos resultados obtidos através do método de efeitos fixos. ${ }^{14}$ É importante ressaltar que a dummy de partidos de centro foi retirada das estimações para evitar o problema de multicolinearidade perfeita entre as variáveis de ideologia política, sendo, portanto, a referência na análise destes parâmetros.

Em relação às receitas disponíveis pelos municípios brasileiros, é possível observar que tanto a receita de transferências como a receita tributária tendem a influenciar de forma positiva praticamente todas as funções orçamentárias avaliadas. É possível avaliar, também, como tais recursos são distribuídos entre as funções: saúde e saneamento, por exemplo, é uma das funções que mais absorvem recursos oriundos de transferências dos governos estaduais e da União, sinalizando que para cada R\$ 1 obtido através desta fonte, $\mathrm{R} \$ 0,19$ são alocados nesta função. De toda forma, este é um resultado que pode ser considerado natural dado o caráter vinculador do mecanismo de transferências aos municípios brasileiros para a provisão de serviços nesta área específica. Outra função que absorve boa parte dos recursos oriundos de transferências é o caso da habitação e urbanismo, cujo coeficiente sinaliza que R \$ 0,12 das transferências são alocadas nesta função. Já em relação à alocação dos recursos oriundos de tributação própria, observa-se que boa parte dos mesmos é alocada na função transportes (coeficiente igual a 0,11 ), sendo relevantes, também, os valores observados para a saúde e saneamento e para o Legislativo (coeficientes aproximadamente iguais a 0,08$)$.

Alguns casos particulares merecem uma apreciação específica, como por exemplo, a função educação e cultura, uma vez que a mesma absorve cerca de $26 \%$ e $31 \%$ das receitas de transferências e das receitas tributárias, respectivamente, configurando, assim, o caso mais significante em termos das funções avaliadas - note que o primeiro destes resultados também pode estar associado ao caráter vinculador do sistema de transferências governamentais associadas à manutenção dos serviços de educação pública pelas prefeituras brasileiras. Adicionalmente, é possível observar que as despesas da função agricultura apresentam relação negativa com o volume de recursos originados por via da tributação local, resultado que pode evidenciar um padrão particular de alocação destes recursos especificamente entre as funções governamentais aqui consideradas. Por fim, é possível observar que as receitas de

13 Teste de Hausman:

$\mathrm{H}_{0}=$ os estimadores do modelo de efeitos fixos e do modelo de efeitos aleatórios são ambos consistentes, mas o de efeitos aleatórios é eficiente;

$\mathrm{H}_{\mathrm{a}}=$ só os estimadores de efeitos fixos são consistentes.

O teste é distribuído através de uma $\chi^{2}$ com n (número de coeficientes estimados) graus de liberdade. Note que em todas as estimações o teste de Hausman não aceita a hipótese nula, ou seja, o método consistente vem a ser o método de efeitos fixos.

14 Os resultados obtidos através dos demais métodos de estimação (efeitos aleatórios e pooled OLS) podem ser solicitados ao autor, caso seja de interesse do leitor. 
transferências não influenciam o comportamento da despesa da função comunicações, um caso singular relativamente aos demais.

Um outro resultado a ser considerado diz respeito à influência do PIB nacional sobre o comportamento das despesas dos municípios brasileiros. Alguns casos são esperados, como ocorre nos casos das funções agricultura, transporte, assistência e previdência, legislativa e educação e cultura, visto que as despesas destas funções são positivamente relacionadas com o ciclo econômico. Por sua vez, de forma contraintuitiva, as despesas das funções saúde e saneamento, comunicações e habitação e urbanismo tendem a decrescer em anos de expansão da produção agregada. Embora seja complexo definir uma razão concreta para tal fenômeno, estes resultados parecem indicar que o próprio comportamento do nível de renda nacional tende a influenciar a forma pela qual os recursos são alocados pelas prefeituras brasileiras, ou seja, períodos de expansões econômicas nem sempre estão associados a maiores gastos públicos de maneira generalizada.

A análise do coeficiente associado à dummy de Lei de Responsabilidade Fiscal permite observar que nem todas as funções sofreram reduções nos valores executados, conforme poderia se esperar. Este resultado de fato ocorre no caso das despesas das funções saúde e saneamento, transporte, comunicações, habitação e urbanismo e legislativo, mas os resultados indicam fenômeno oposto no caso das funções agricultura, assistência e previdência e educação e cultura. Assim, a instituição de tal lei pode ter provocado não só uma redução dos gastos totais, mas também um "efeito composição" dos gastos realizados pelas prefeituras brasileiras.

Quanto aos coeficientes associados aos termos de tendência, é possível observar que os gastos das funções agricultura, assistência e previdência, legislativa e educação e cultura crescem ao longo do período analisado, ao passo que os gastos das funções transporte e habitação e urbanismo sofrem redução. Especificamente no caso da função saúde e saneamento, é possível constatar que há uma tendência positiva e crescente desta ao longo do tempo, em função dos sinais positivos associados ao termo de tendência linear e de tendência quadrática. Em cada um dos demais casos, é possível observar que estes dois parâmetros apresentam sinais invertidos, exceto no caso da função habitação e urbanismo, para o qual o termo de tendência quadrática é estatisticamente nulo. De qualquer forma, estes resultados permitem observar um novo efeito composição das despesas públicas, vigente ao longo do tempo.

No tocante às demais variáveis explicativas, inclusive aquelas referentes às dummies de ano e às dummies de partido político, são apresentadas análises separadas para cada uma das funções orçamentárias, em função das especificidades observadas em cada caso, conforme o exposto a seguir. 


\subsection{Agricultura}

O primeiro caso aqui avaliado é, a princípio, distinto do esperado pela teoria dos ciclos políticos oportunistas, uma vez que os valores executados em anos eleitorais são, em média, menores que os executados nos demais anos. O coeficiente associado a dummy de ano eleitoral é estatisticamente significativo e sugere que em tais anos a retração das despesas é da ordem de R \$ 1,60 per capita. Por sua vez, como nenhuma das dummies de ideologia política é estatisticamente significativa, pode-se inferir que as despesas municipais da função agricultura não estariam sujeitas ao fenômeno do ciclo partidário.

Quanto às variáveis de controle, é possível observar que tanto o alinhamento com o governo estadual como com o governo federal influencia negativamente o volume das despesas em agricultura. Sobre as variáveis demográficas, observa-se que uma proporção maior de jovens e de idosos tende a elevar as despesas nesta função, enquanto municípios com maior porte populacional tendem a executar relativamente menos recursos na mesma. Em particular, este último resultado pode estar associado ao fato de que municípios de menor porte podem ter um vínculo mais sólido com atividades de natureza agrária, justificando, assim, maiores recursos executados nesta função. É interessante ressaltar, adicionalmente, a não-significância estatística do coeficiente associado ao grau de urbanização, contrariando a idéia de que municípios mais urbanizados alocariam consequentemente menores recursos nesta função. Desta forma, tomados em seu conjunto, estes resultados podem indicar que o grau de interação da gestão orçamentária local com as atividades municipais de caráter agrícola pode ser limitado, provavelmente porque estas estão normalmente associadas a fontes de financiamento e aportes de recursos públicos muitas vezes disponibilizados pelo governo federal e pelo governo estadual de forma direta (financiamentos e renegociações, entre outros), ou seja, sem que a administração local atue diretamente nesta função. Tal fato pode inclusive justificar o sinal negativo das dummies de alinhamento político com os governos estadual e federal já que, quando tal fato ocorre, existe a possibilidade de maiores aportes financeiros diretos por parte de tais níveis superiores de governo, diminuindo assim a necessidade dos recursos locais.

\subsection{Saide e Saneamento}

O caso das despesas de saúde e saneamento vem a ser significativo nesta análise dado que o coeficiente referente à dummy de ano eleitoral é estatisticamente significante e igual a 8,68. Entre todas as funções analisadas, este é o maior valor observado para tal coeficiente, sugerindo, assim, que esta seria uma das funções mais sujeitas a manipulações eleitoreiras. Quanto às dummies de ideologia política, observa-se também que todas elas são positivas e estatisticamente significantes, indicando as- 
sim que todos os grupos partidários despendem um volume de recursos superior ao executado pelos partidos de centro.

No que diz respeito às variáveis de controle, somente o alinhamento político com o governo estadual faz com que as despesas municipais sejam maiores - neste caso, o coeficiente associado à dummy de alinhamento com o governo federal assume valor estatisticamente igual a zero. Já em relação às variáveis demográficas, os resultados podem ser considerados intuitivos uma vez que a proporção de idosos e de jovens residentes nos municípios brasileiros, bem como a taxa de urbanização e o tamanho da população influenciam de forma positiva o montante de recursos executados pelas administrações municipais em ações associadas à saúde e saneamento público.

\subsection{Transporte}

A estimação para o caso da função transporte permite constatar que somente o fenômeno do ciclo eleitoral é observado, visto que as dummies de ideologia política são todas estatisticamente nulas. Os resultados indicam que a dummy de ano eleitoral é estatisticamente significante e sugere que em tais anos há um aumento da ordem de R\$2,08 per capita. Adicionalmente, nem o alinhamento político com o governo estadual nem o alinhamento político com o governo federal influenciam o valor das despesas executadas em tal função - neste caso, uma explicação reside na possibilidade de que os investimentos nesta área são normalmente realizados de forma direta pela gestão estadual e federal e, assim, o alinhamento político com a unidade local pode ter influência limitada sobre os recursos executados diretamente pelas prefeituras brasileiras. Assim, por exemplo, é possível que este alinhamento faça com que a unidade local esteja recebendo aportes financeiros dos governos estadual e federal em tal área através, por exemplo, da atuação de parlamentares representanes daquela região, entre outros mecanismos possíveis.

Por fim, é possível observar que em relação às variáveis demográficas há uma diferença significativa em relação ao caso das despesas de saúde e saneamento, pois todas apresentam relação negativa com o volume de recursos executados pelas prefeituras brasileiras. Em particular, tal resultado parece contrariar a percepção de que haveria uma correlação positiva entre maiores investimentos em transportes e maiores níveis de urbanização e/ou maiores portes populacionais, ou seja, este resultado parece sugerir que os investimentos nesta área são maiores justamente nas localidades menos urbanizadas e de menor porte populacional, ainda desprovidas da infraestrutura gerada por este tipo de despesa. 


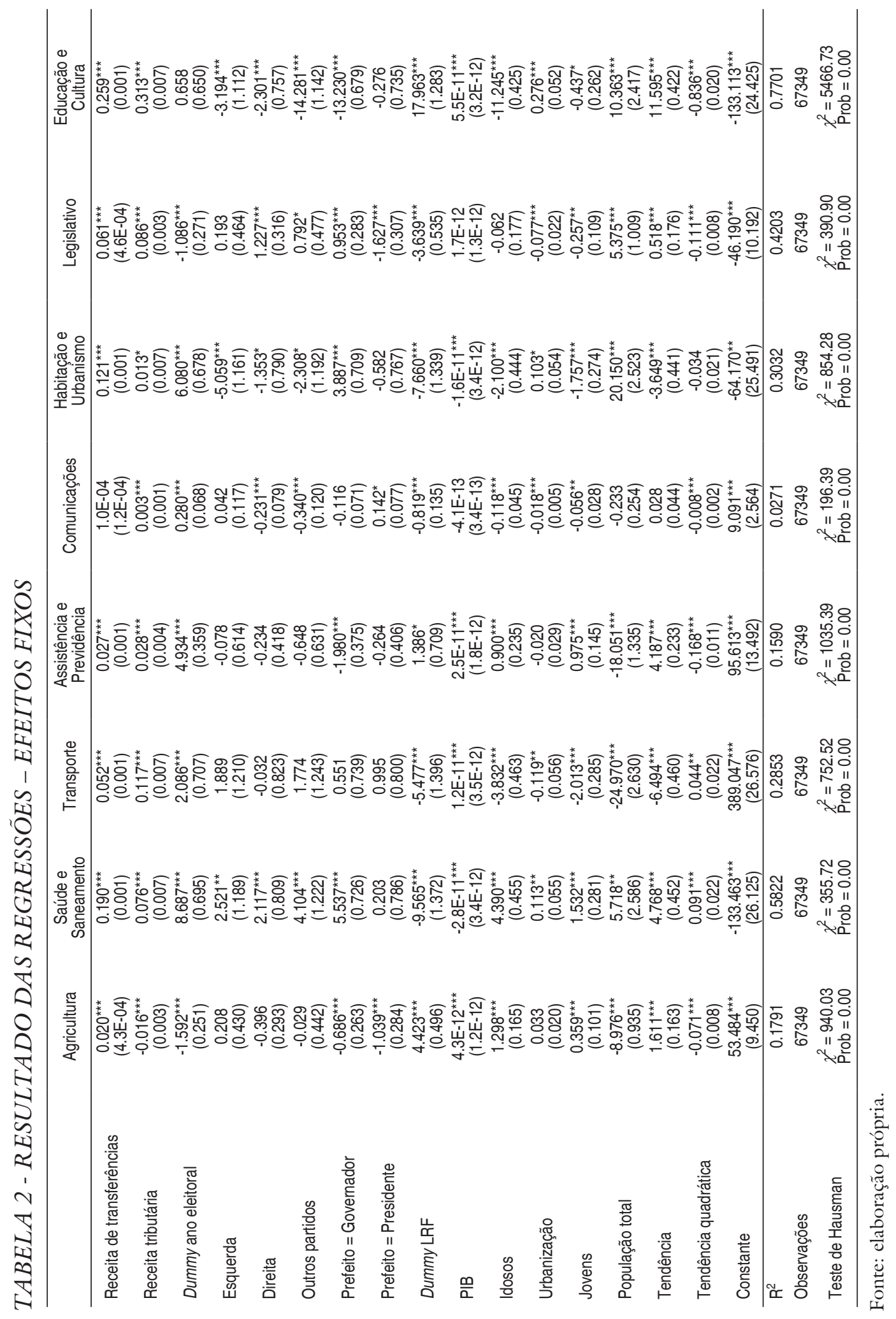




\subsection{Assistência e Previdência}

De forma semelhante ao caso da função transporte, observa-se também que as despesas de assistência e previdência sofrem aumentos significativos em anos eleitorais, em um montante aproximadamente igual a $\mathrm{R} \$ 5$ por habitante. Contudo, a influência das diferenças partidárias parece ser estatisticamente nula neste caso. Quanto às variáveis de controle, somente o alinhamento com o governo estadual apresenta influência estatisticamente significante sobre a variável em questão e, em particular, negativa. Quanto às variáveis de natureza demográfica, observa-se um resultado bastante próximo do observado no caso da função agricultura: uma proporção maior de idosos e jovens residindo nos municípios brasileiros tende a fazer com que as despesas de assistência e previdência sejam mais elevadas - tal resultado pode ser considerado intuitivo, pois tende a ser mais elevada a demanda por assistência social pública quanto mais elevada for a concentração da população nestas duas faixas etárias. Adicionalmente, observa-se que as despesas desta função são também maiores quanto menor o porte populacional de um dado município. ${ }^{15}$

\subsection{Comunicação}

A análise da função em questão pode ser vista como relevante neste contexto dado o provável interesse da gestão municipal em procurar uma difusão maior das suas realizações, especialmente nos anos eleitorais, através dos veículos de mídia. Os resultados econométricos permitem inferir que tal hipótese é aparentemente válida, dado o valor positivo e estatisticamente significativo do coeficiente associado à dummy de ano eleitoral (valor igual a 0,28 ). Em relação às dummies de ideologia política, observa-se coeficiente estatisticamente significante somente para os partidos de direita, igual a $-0,23$, sendo a dummy associada aos partidos não classificados também estatisticamente significativa e negativa. Finalmente, os resultados sugerem que somente um dos alinhamentos partidários, qual seja, com o governo federal, tende a alterar positivamente o volume de recursos executados por tais unidades neste caso, é estatisticamente nulo o coeficiente associado ao alinhamento partidário com o governo estadual. No que diz respeito às variáveis de controle demográficas, somente o coeficiente associado à população total é estatisticamente nulo - os demais coeficientes são todos significantes e sugerem uma relação negativa com esta categoria de despesa pública.

15 Neste caso, o grau de urbanização apresenta influência nula sobre as despesas desta função. 


\subsection{Habitação e urbanismo}

$\mathrm{O}$ valor associado à dummy de ano eleitoral permite inferir que as despesas da função habitação e urbanismo são significativamente maiores em anos eleitorais, estando abaixo apenas dos impulsos observados no caso da função saúde e saneamento - em anos eleitorais, tais despesas tendem a ser mais elevadas em aproximadamente R \$ 6 por habitante. Por outro lado, de forma oposta à vista na função saúde e saneamento, todas as dummies de ideologia são negativas (estatisticamente significativas). No caso dos partidos de esquerda, chama a atenção o valor elevado que tal coeficiente assume $(-5,05)$, indicando, assim, menores investimentos por parte deste partido em um montante não-desprezível relativamente aos partidos de centro.

Finalizando a análise, o caso das despesas de habitação e urbanismo tende a sofrer influência estatisticamente significativa e positiva do alinhamento político com o governo estadual, embora o alinhamento com o governo federal tenha influência estatisticamente nula. Este resultado também pode ser visto como particular nesta análise uma vez que, embora os governos estadual e federal sejam responsáveis por parte significativa dos investimentos realizados em projetos de habitação popular, por exemplo, os resultados indicam que o alinhamento ideológico com o governo estadual especificamente pode permitir que a própria administração local atue de forma mais incisiva nesta função. Por sua vez, conforme poderia se esperar, municípios com maiores taxas de urbanização e maiores portes populacionais são aqueles que mais investem recursos nesta função. Maiores investimentos são também observados nos municípios com menores proporções de jovens e idosos residentes.

\subsection{Legislativa}

Intuitivamente, seria esperado um comportamento particular das despesas da função legislativa em função do calendário eleitoral, dado um provável maior grau de atuação dos vereadores com vistas a ampliar suas chances de permanência nas câmaras legislativas dos municípios brasileiros. Contudo, os resultados sugerem justamente o oposto em função do valor negativo que o coeficiente associado à dummy de ano eleitoral assume. Por sua vez, as dummies associadas aos partidos de direita e ao grupo dos partidos não classificados assumem valores positivos e estatisticamente não-nulos, ou seja, prefeituras comandadas por tais grupos partidários tendem a ter legislativos com maior volume de recursos executados.

Analisando, por fim, as variáveis de controle, observa-se um resultado singular nesta função visto que, embora o alinhamento partidário com o governo estadual 
influencie positivamente as despesas legislativas, ocorre justamente o oposto caso o alinhamento partidário seja em relação ao governo federal. Caso estes dois alinhamentos ocorram simultaneamente, o impacto líquido parece ser negativo em função do maior valor absoluto do segundo coeficiente $(-1,627)$ relativamente ao primeiro $(0,953)$. Quanto aos indicadores demográficos, excetuando o coeficiente associado à proporção de idosos, todos apresentam significância estatística variando apenas o sinal: enquanto municípios mais populosos alocam relativamente mais recursos nesta função comparativamente aos menores, observa-se que municípios com menores proporções de jovens e com menores graus de urbanização são aqueles que mais executam recursos em tal função.

\subsection{Educação e Cultura}

A última função avaliada neste estudo vem a ser relevante neste contexto já que, conforme discutido anteriormente, a proporção de recursos municipais alocados nesta função é significativa. Ademais, é importante notar que, de forma semelhante à função saúde e saneamento, tais despesas têm forte apelo popular e político, justificando assim tal investigação. Contudo, os resultados das estimações permitem observar que nenhuma manipulação eleitoral é observada nesta função dada a não-significância estatística do coeficiente associado à dummy de ano eleitoral. Por outro lado, ressaltase que todas as dummies de ideologia partidária são estatisticamente significantes e, em particular, negativas, sugerindo, assim, menores investimentos municipais por parte dos partidos de esquerda e de direita nesta função, relativamente aos partidos de centro. É importante ressaltar, também, o caso do grupo dos partidos não classificados e o valor expressivo que seu coeficiente assume $(-14,28)$.

Da mesma forma que a observada no caso da função assistência e previdência, observa-se que somente o alinhamento político com o governo estadual influencia, e de forma negativa, o comportamento desta categoria de despesa pública, já que o alinhamento com o governo federal apresenta influência nula sobre tais despesas. Teoricamente, ambos os alinhamentos deveriam ter influência nula uma vez que parte significativa das despesas municipais realizadas nesta área tem como base recursos oriundos de transferências constitucionais e que, portanto, independeriam de influência política. Contudo, os resultados parecem não corroborar tal percepção e, em particular, podem indicar que a execução de recursos municipais tende a ser menor visto que os mesmos podem estar sendo substituídos pelo governo estadual, caso haja o alinhamento ideológico entre tais instâncias governamentais - novamente, pode-se inclusive considerar a ação dos membros do Legislativo estadual como forma de canalização destes recursos. 
No que diz respeito às variáveis demográficas alguns resultados podem ser considerados naturais, como ocorre no caso da proporção de idosos, que assume valor negativo, e no caso do grau de urbanização e da população, que assumem valores positivos. Contudo, um resultado aparentemente contraditório ocorre justamente no caso da proporção de jovens, indicando que quanto maior a proporção da população situada nesta faixa etária, menores são as despesas de educação e cultura executadas pelas prefeituras brasileiras ao longo do período avaliado.

\section{CONSIDERAÇÕES FINAIS}

O presente artigo teve como propósito fundamental prover evidências de como as prefeituras brasileiras alocam seus recursos disponíveis entre as diversas funções governamentais que compóem seus respectivos orçamentos. Em termos mais específicos, o trabalho procurou prover informações sobre como estas diferentes funções têm se comportado ao longo dos 16 contemplados na amostra tanto em termos de longo prazo, ou seja, averiguando a presença de eventuais tendências, como em termos de curto prazo, procurando avaliar se tais categorias estariam sujeitas ao fenômeno do ciclo eleitoral. Adicionalmente, os testes procuraram prover resultados que permitissem avaliar como as diferenças partidárias entre as prefeituras brasileiras influenciam a forma pela qual estas alocam seus recursos disponíveis. Finalmente, o estudo procurou averiguar, também, como a instituição da Lei de Responsabilidade Fiscal tem afetado o comportamento das funções orçamentárias dos municípios brasileiros.

Os resultados indicam que o fenômeno do ciclo eleitoral é observado de forma mais expressiva em algumas funções específicas, quais sejam, saúde e saneamento, assistência e previdência, habitação e urbanismo e transportes. Especificamente para as duas primeiras funções, é possível inferir que tais manipulações, elevadoras das suas respectivas despesas, podem ser canalizadas de forma relativamente mais imediata à população, uma vez que estas são, normalmente, foco de forte apelo político junto aos eleitores. De toda forma, os resultados indicam que nem todas as funções avaliadas são alvos destas distorções e em alguns casos, as mesmas são até negativas, como no caso das funções agricultura e legislativa. Assim, tomados em conjunto, tais resultados sugerem um efeito composição do orçamento municipal especificamente em anos eleitorais, com algumas funções sofrendo expansões de despesas, e outras sofrendo retrações, de forma relativamente semelhante à observada em Drazen e Eslava (2005).

Especificamente a respeito dos grupos partidários avaliados, as principais distinções observadas indicam que os partidos de esquerda e de direita (assim como o grupo de 
partidos não classificados) realizam maiores empenhos de recursos nas funções saúde e saneamento mas, por outro lado, realizam menores despesas nas funçôes habitação e urbanismo e educação e cultura. Desta forma, estas constatações permitem observar que o fenômeno do ciclo partidário é existente, mas de forma relativa e específica a algumas funções orçamentárias. Já no que diz respeito às variáveis demográficas, é interessante observar que as proporções de idosos e de jovens têm influência semelhante sobre algumas despesas: as duas variáveis estão positivamente associadas a maiores gastos em agricultura, saúde e saneamento, assistência e previdência, por um lado, mas a menores gastos em transporte e educação e cultura, por outro lado. De qualquer maneira, é possível observar que a composição etária dos municípios brasileiros apresenta influência significativa sobre a estrutura de seus gastos.

Por fim, em termos de uma avaliação de longo prazo das despesas avaliadas, observase um efeito "composição" dos recursos municipais já que é observada uma tendência crescente para algumas funções orçamentárias (saúde e saneamento, assistência e previdência e educação e cultura, notadamente) em detrimento de uma queda dos recursos alocados em outras funções (especialmente transporte e habitação e urbanismo). Tomados em seu conjunto, estes resultados aparentemente indicam que as despesas de natureza corrente têm crescido em função da queda das despesas de investimento das prefeituras brasileiras. Adicionalmente, conforme os resultados obtidos, a própria LRF fez com que tal efeito composição se fizesse também observado.

\section{REFERENCLIAS}

ALESINA, Alberto. Macroeconomic policy in a two-party system as a repeated game. Quarterly Journal of Economics, n. 102, p. 651-678, 1987.

; ROUBINI, Nouriel; COHEN, Gerald D. Political cycles and the macroeconomy. Cambridge: the MIT Press, 1997.

BERGER, Helge; WOITEK, Ulrich. Searching for political business cycle in Germany. Public Choice, n. 91, p. 179-197, 1997.

BITTENCOURT, Jeferson Luís. Evidências de ciclo politico na economia brasileira: um teste para a execução orçamentária dos governos estaduais - 1983/2000. 2002. Dissertação (Mestrado). Programa de pós-graduação em Economia. Faculdade de Ciências Econômicas. Universidade Federal do Rio Grande do Sul.

BOTELHO, Ricardo. Determinantes do comportamento fiscal dos estados brasileiros. 2002. Dissertação (Mestrado) - Instituto de Pesquisas Econômicas - Faculdade de Economia, Administração e Contabilidade - Universidade de São Paulo.

BRENDER, Adi; DRAZEN, Allan. Political budget cycles in new versus established democracies. Journal of Monetary Economics, v. 52, p. 1271-1295, 2005. 
COSSIO, Fernando Andrés Blanco. O comportamento fiscal dos estados brasileiros e seus determinantes políticos. Economia, v. 2, n. 1, p. 207-258, 2001.

DRAZEN, Allan; ESLAVA, Marcela. Electoral manipulation via expenditure composition: theory and evidence. NBER Working Papers, $\mathrm{n}^{\circ}$ 11085. Disponível em: <http://www.nber.org/papers/w11085>. Acesso em: 13 jan. 2006.

HIBBS, Douglas A. Jr. Political parties and macroeconomic policy. American Political Science Review, n. 71, 1977.

MENEGUIN, Fernando B.; BUGARIN, Mauricio Soares. Reeleição e política fiscal: um estudo dos efeitos da reeleição nos gastos públicos. Economia Aplicada, v. 5, n. 3,2001 .

NAKAGUMA, Marcos Yamada. Ciclos politicos e resultados eleitorais: um estudo sobre o comportamento do eleitor brasileiro. 2006. Dissertação (Mestrado). Instituto de Pesquisas Econômicas. Faculdade de Economia, Administração e Contabilidade. Universidade de São Paulo.

NORDHAUS, William. The political business cycle. Review of Economic Studies, n. 42, p. 169-190, 1975.

NUNES, Selene P.; NUNES, Ricardo da C. Dois anos da Lei de Responsabilidade Fiscal do Brasil: uma avaliação dos resultados à luz do modelo do fundo comum. Departamento de Economia - Universidade de Brasília, 2003. (Série Textos para discussão, $\left.\mathrm{n}^{\mathrm{O}} 276\right)$.

PERSSON, Torsten; TABELLINI, Guido. Do electoral cycles differ across political systems? IGIER Working Paper, n. 232, 2003.

RODRIGUES, Leôncio Martins. Partidos, ideologia e composição social: um estudo das bancadas partidárias na Câmara dos Deputados. São Paulo: Editora Edusp, 2002.

ROGOFF, Kenneth; SIBERT, Anne. Elections and macroeconomic policy cycles. Review of Economic Studies, n. 55, p. 1-16, 1988.

ROGOFF, Kenneth. Equilibrium political budget cycles. The American Economic Review, v. 80, n. 1, p. 21-36, 1990.

SAKURAI, Sergio Naruhiko. Political business cycles: procurando evidências empíricas para os municípios paulistas. Revista de Economia Aplicada, n. 1, v. 11, p. 27-54, 2007.

SHI, Min; SVENSSON, Jakob. Political budget cycles: do they differ across countries and why? Journal of Public Economics, v. 90, p. 1367- 1389, 2006.

. Political budget cycles: a review of recent developments. Nordic Journal of Political Economy, v. 29, n.1, p. 67-76, 2003.

TUFTE, Edward. Political control of the Economy. New Jersey: Princeton University Press, 1978. 